\title{
La Real Expedición Filantrópica de Balmis: La primera campaña de vacunación mundial
}

\author{
Pérez-Molphe Montoya Eugenio*, Salinas Miralles Eva**
}

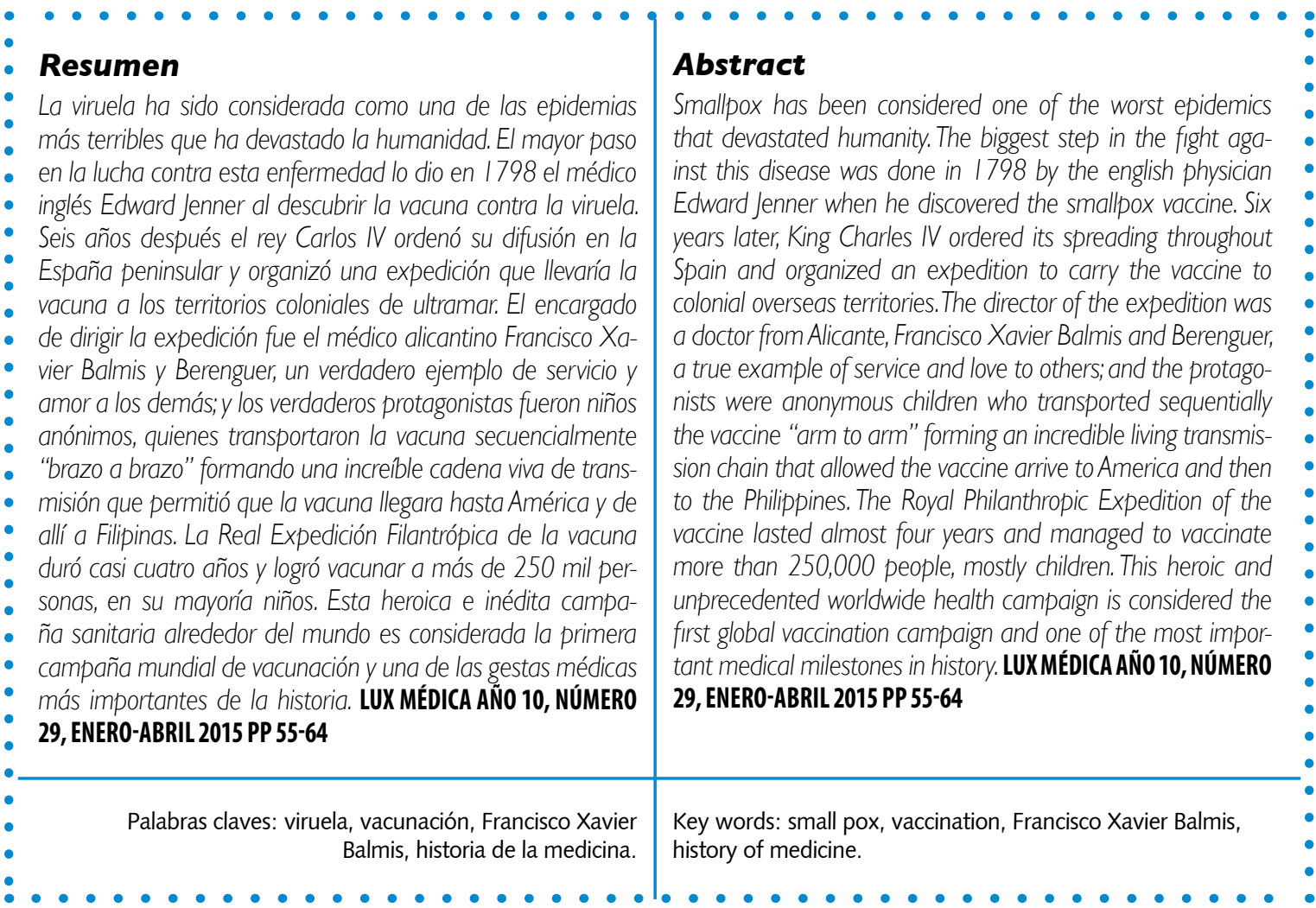

* Estudiante de sexto semestre de la Licenciatura en Biología del Centro de Ciencias Básicas de la Universidad Autónoma de Aguascalientes. ** Dra. en Medicina. Profesor-Investigador de Inmunología del Departamento de Microbiología del Centro de Ciencias Básicas de la Universidad Autónoma de Aguascalientes.

Fecha de recibido: 6 de febrero 2015

Fecha de aceptación: 28 de febrero 2015

Correspondencia:

Dra. Eva Salinas Miralles. Laboratorio de Inmunología (Lab \#5). Edificio 202. Departamento de Microbiología. Centro de Ciencias Básicas, Universidad Autónoma de Aguascalientes. Avenida Universidad \# 940, Código Postal 20131. Aguascalientes, Ags., México. Teléfono: 9108424. Correo electrónico: emsalin@correo.uaa.mx 


\section{Introducción}

La viruela fue una enfermedad infecciosa, altamente contagiosa, que azotó a la humanidad desde la antigüedad hasta su erradicación en $1980 .^{1}$ Está causada por un virus perteneciente a la familia Orthopox, cuyos miembros producen enfermedades similares a la humana en otros animales como el cerdo, los monos, los camellos y las vacas. ${ }^{2}$ Esta afección tan devastadora en los humanos era mortal en el $25 \%$ de los casos, y a la alta tasa de mortalidad había que añadir que causaba discapacidad (ceguera como secuela) y estigmas o cicatrices desfigurantes generadas por las numerosas y agresivas pústulas que desarrollaban los afectados en cuerpo y rostro. ${ }^{1,3}$

Aunque el dato exacto de su aparición no es claro, era conocida desde la más lejana antigüedad en las civilizaciones asirias, babilónicas, egipcias y chinas, describiendo la enfermedad por primera vez el médico persa conocido como Rahazés, en su libro De variolis et morbilis, en el siglo X.1 La viruela llegó posteriormente a Europa donde se extendió provocando grandes epidemias entre los siglos XVI a XVIII. Fue introducida en América en 1520 por un esclavo negro que viajó en una expedición española dirigida por Pánfilo Narváez y para el siglo XVII se había extendido por toda América. ${ }^{4,5}$ La viruela fue especialmente agresiva en las poblaciones amerindias ya que no habían tenido contacto alguno con la enfermedad, lo que hacía que la tasa de mortalidad fuera superior en poblados indígenas que en ciudades con mayoría hispana, llegando a diezmarse la población americana de un $20 \%$ a un $50 \%$ durante el siglo XVI y XVII. ${ }^{6}$

Entre los primeros intentos para su prevención destacó el uso de la "variolación", técnica de origen asiático que consistía en inocular a un individuo sano por vía cutánea cantidades pequeñas de líquido obtenido de las pústulas de una persona enferma de viruela. De esta manera, mayoritariamente se inducía una forma leve de la enfermedad en comparación con la enfermedad adquirida de forma natural por vía respiratoria. Sin embargo, no dejaba de tener efectos secundarios (cicatrices y posible contagio de sífilis) y en algunos casos era mortal (aproximadamente $2 \%$ de los casos). ${ }^{4}$ Pese al rechazo inicial, finalmente esta técnica fue aceptada y difundida en Europa y América. El uso de la variolación, aunque fue parcialmente exitosa en el intento de luchar contra la viruela, contribuyó a un mayor número de contagios y a que la enfermedad se siguiera extendiendo. $^{5}$

El gran paso en la erradicación definitiva de la enfermedad se lo debemos al médico inglés Edward Jenner en 1798. Basándose en simples observaciones que posteriormente demostró científicamente, concluyó que la inoculación cutánea en una persona sana con líquido (linfa) obtenido de la pústula de una vaca enferma de la "viruela de las vacas", una enfermedad leve y sin secuelas para los humanos, generaba en el individuo protección frente a la "viruela 
humana", estableciendo así el primer método de vacunación (del latín vacca). ${ }^{7}$ En la persona vacunada con la linfa vacuna se generaba una pústula en el lugar de inoculación, de la que entre 11 a 14 días después se tomaba linfa para inocular a otra persona que no hubiese sufrido nunca la viruela. Demostradas las ventajas de la vacunación con la linfa vacuna frente a la variolación: ausencia de pústulas o cicatrices en la cara y de contagios, la vacuna de Jenner se difundió de manera inmediata por Europa.,

En este contexto se inicia una de las gestas más importantes de la historia de la medicina: La Real Expedición Filantrópica de la Vacuna (1803-1806). Esta expedición se enmarca dentro del contexto del Siglo de las Luces y de la llustración, en el que se lucha por romper con el oscurantismo de años anteriores, por abrirse a los nuevos conocimientos científicos y por dignificar al ser humano. ${ }^{8}$ Para ello se financiaron múltiples expediciones científicas a todos los confines del mundo aún poco conocidos con fin de obtener información en botánica, cartografía, zoología, mineralogía y arqueología, entre otras ciencias. ${ }^{1}$ Sin embargo La Real Expedición Filantrópica de la Vacuna se distinguió por su carácter humanista y tuvo como objetivo beneficiar a las poblaciones de las entonces colonias españolas en América y Filipinas del gran descubrimiento de la vacuna contra la viruela. 4,9

El encargado de la expedición fue un médico español, nacido en Alicante (Valencia) en 1753, y proveniente de una familia de cirujanos: Francisco Xavier Balmis y Berenguer (figura 1). Este hombre ya había viajado a México en 1786 como cirujano mayor del Hospital Militar Amor de Dios en la ciudad de México y durante su estancia realizó investigaciones médico-botánicas sobre el agave y la begonia que culminaron con la publicación en 1794, ya de regreso a España, de un artículo sobre los efectos terapéuticos de estas plantas en el tratamiento de la sífilis. ${ }^{1} \mathrm{Al}$ conocer los trabajos de Jenner, dio un giro radical en sus investigaciones y empezó a interesarse por el estudio de la viruela. Cuando la vacuna llega a España en 1800, Balmis se convierte en un prestigiado vacunador. Inspirado por su deseo de que los médicos practicaran la vacunación y dándose cuenta de la dificultad que suponía que los principales textos no estuvieran en castellano, decide traducir en 1803 la obra Tratado histórico y práctico de la vacuna, del autor francés Moreau de la Sarthe. ${ }^{1,10}$ Además de su vasto conocimiento sobre la técnica de vacunación, Balmis poseía cualidades que lo hacían idóneo para dirigir la expedición. Era un hombre que exigía lo máximo a sus compañeros y a sí mismo. De talante optimista, afrontaba los peligros con valentía. ${ }^{4}$ Como médico era moderno e incluso adelantado a su época. Defensor de la medicina pública y gratuita y precursor de la medicina preventiva; un gran organizador que fue la clave de su éxito durante la expedición. Pero la cualidad que lo haría brillar más fue su entrega y preocupación por los demás que 
al final fue lo que lo hizo ideal para una empresa filantrópica que marcó un hito en la Historia de la Medicina ${ }^{8}$ y lo convirtió en un pionero de la vacunación internacional. ${ }^{3,11}$

Figura 1. Fotografía del busto de bronce de Francisco Xavier Balmis y Berenguer que fue donado por el Club Rotario de Ciudad de México a la

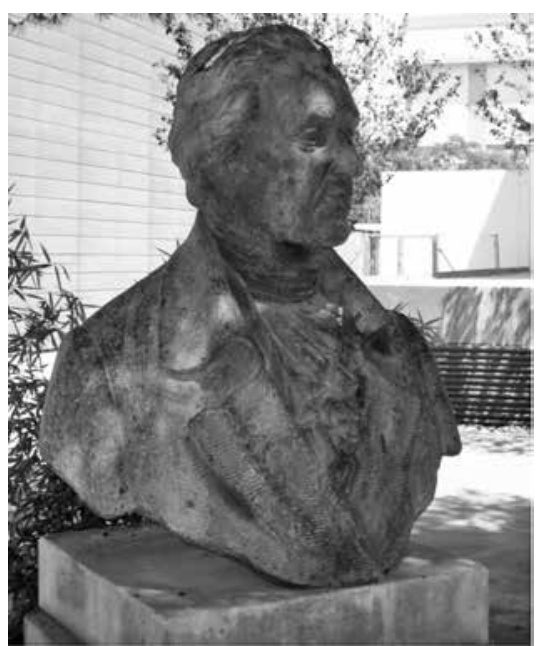
Facultad de Medicina de Alicante, España. Fotografía de Eva Salinas.

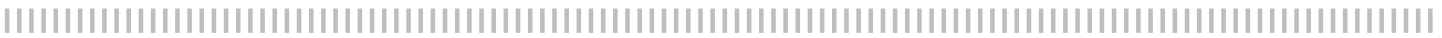

\section{Origen de la Expedición}

En las colonias americanas, la vacuna de Jenner llegaba a cuentagotas en forma de hilas impregnadas de linfa vacunal y guardadas entre vidrios. Así, se realizaron las primeras vacunaciones en lugares con fácil acceso al mar donde los médicos locales recibían la linfa y rápidamente la inoculaban, intentando generar una cadena de portadores para propagarla a los alrededores. Sin embargo la propagación de la vacuna no era exitosa ya que en ocasiones la linfa estaba mal conservada y era inefectiva, o se interrumpía la cadena de transmisión por falta de portadores. ${ }^{3}$

En 1798 la infanta Luisa Fernanda enfermó de viruela y aunque sobrevivió quedó con cicatrices desfigurantes. ${ }^{2}$ En consecuencia, su padre, el rey Carlos IV ordenó la variolación de su familia y de toda la población civil no afectada. Un año después, una copia del libro de Jenner llegó a manos del rey, quien sensibilizado por las cicatrices que la variolación había dejado en su familia vio esperanzas contra la enfermedad en el método preventivo de Jenner y en un edicto real anunció en 1800 la distribución de la vacuna por tierras españolas. ${ }^{5}$ Dos años después se desató una gran epi- demia de viruela en el Virreinato de Nueva Granada (actual Colombia) que llegó a oídos del monarca. Los gobernadores locales suplicaron la ayuda del Rey. La situación en Nueva Granada era terrible y otras regiones de América también tenían problemas con esta enfermedad en forma de epidemias esporádicas. ${ }^{6}$ En ese momento, el rey decidió actuar y llamó a consultas al oriundo de Chiapas y físico de la corte, Dr. José Flores quien le recomendó enviar en una corbeta española la vacuna a la América Hispana y si fuese posible hasta Filipinas. En marzo de 1803 el Consejo de Indias aprobó el plan y anunció la expedición. Se dictó que la financiación de la expedición correría a cargo de la Hacienda Pública, distribuyendo los gastos de la siguiente manera: los derivados de navegación y transporte de los expedicionarios estarían pagados por la Real Hacienda, pero al llegar a los territorios coloniales serían los poderes públicos locales los encargados de sufragar esos gastos. Debido al gran dramatismo de la situación el gobierno actuó con prontitud, transcurriendo solo 8 meses desde la aprobación del proyecto hasta su inicio. ${ }^{3,5,6}$

En ese mismo año Balmis había traducido la obra de Moreau de la Sarthe y se 
había convertido en un destacado practicante de la vacunación, en su mayoría de forma gratuita. Conocedor de los planes de la corte e interesado en hacerse cargo del proyecto, presentó su propuesta para la expedición. Propuso como método de transporte más adecuado para el fluido vacunal "la vacunación brazo a brazo" y adjuntó un reglamento que dirigiría la convivencia entre los miembros de la expedición y las obligaciones de cada uno de los comisionados. Al mismo tiempo Balmis visitó o escribió a médicos influyentes de la Corte para obtener su favor. A finales del mes de junio, la Junta de Cirujanos de la Cámara aprobó el proyecto de Balmis. ${ }^{11}$ Tras el visto bueno de Carlos IV, el mismo rey procedió con los nombramientos de los integrantes de la que fue la mayor hazaña médica de la llustración.8 Como director, Francisco Xavier Balmis y Berenguer, junto a los ayudantes José Salvany y Lleopart (que luego fue nombrado subdirector de la expedición), Manuel Julián Grajales y Antonio Gutiérrez Robredo. Los practicantes Francisco Pastor Balmis y Rafael Lozano Pérez, y los enfermeros Basilio Bolaños, Pedro Ortega y Antonio Pastor. Además 22 niños, que mediante una cadena profiláctica de brazo a brazo serían los portadores de la vacuna y como cuidadora de los niños Isabel Sendales y Gómez, Rectora de la Casa de Expósitos de La Coruña y considerada la primera enfermera de la historia de la medicina hispana. , $, 6,8$

La colecta de niños fue un tanto difícil ya que las familias no querían dejar ir a sus niños en una expedición de estas características. Entonces se buscó conseguirlos en familias desestructuradas. A cambio, se les daría hospedaje y los cuidados estarían pagados por el Erario Público. Aun así, fue tarea imposible, por lo que se decidió elegir niños sin padres conocidos. Además, no todos los niños cumplían con las características necesarias. Debían de estar sanos, sin haber padecido la viruela y con menos de 10 años de vida. La elección de los niños recayó en Balmis. ${ }^{6}$ Él eligió un total de 22 niños huérfanos de entre 4 y 10 años de la Casa de Expósitos de La Coruña, en acuerdo con la rectora del orfanato Isabel Sendales y Gómez. ${ }^{2}$ Mientras tanto, el ministro de Gracia y Justicia dictó la Real Orden de 1 septiembre que ordenaba a las autoridades coloniales, tanto civiles como religiosas, a apoyar la expedición y se les comunicaba el objetivo de la misma. ${ }^{11}$

Como en los modernos programas de vacunación se definieron los siguientes objetivos: se difundiría de manera gratuita la vacuna entre la población, se entrenaría a los sanitarios locales para que administrasen la vacuna, se crearía las Juntas de Vacunas o centros permanentes para asegurar la conservación, producción y abastecimiento de vacuna activas y que permitiesen establecer un modelo homogéneo de actuaciones y evaluaciones.4,3 Además, para el cuidado de la estabilidad de la vacuna se dispuso de los siguientes materiales: 2000 pares de vidrios para mantener el fluido vacuno, cera para lacrar, fieltro negro para envolver, lancetas para las incisiones, 6 libros en blanco para anotar los resultados y las posibles variaciones de la vacuna en los diferentes climas y altitudes de América, 4 barómetros y 4 termómetros. También llevaron 500 ejemplares de la traducción al castellano realizada por Balmis del libro Tratado histórico y práctico de la vacuna, de Moreau de la Sarthe, que se convirtió en el manual oficial de vacunación para difundir el procedimiento en la América Hispana. ${ }^{3}$

\section{La Expedición}

El 30 de noviembre de 1803, la corbeta María Pita zarpó desde el puerto de La Coruña llevando a bordo la expedición de Balmis y habiendo vacunado a los dos primeros niños antes de partir (ver figura 2). ${ }^{3}$ Debido al elevado número de tripulantes, las condiciones en los compartimentos del 


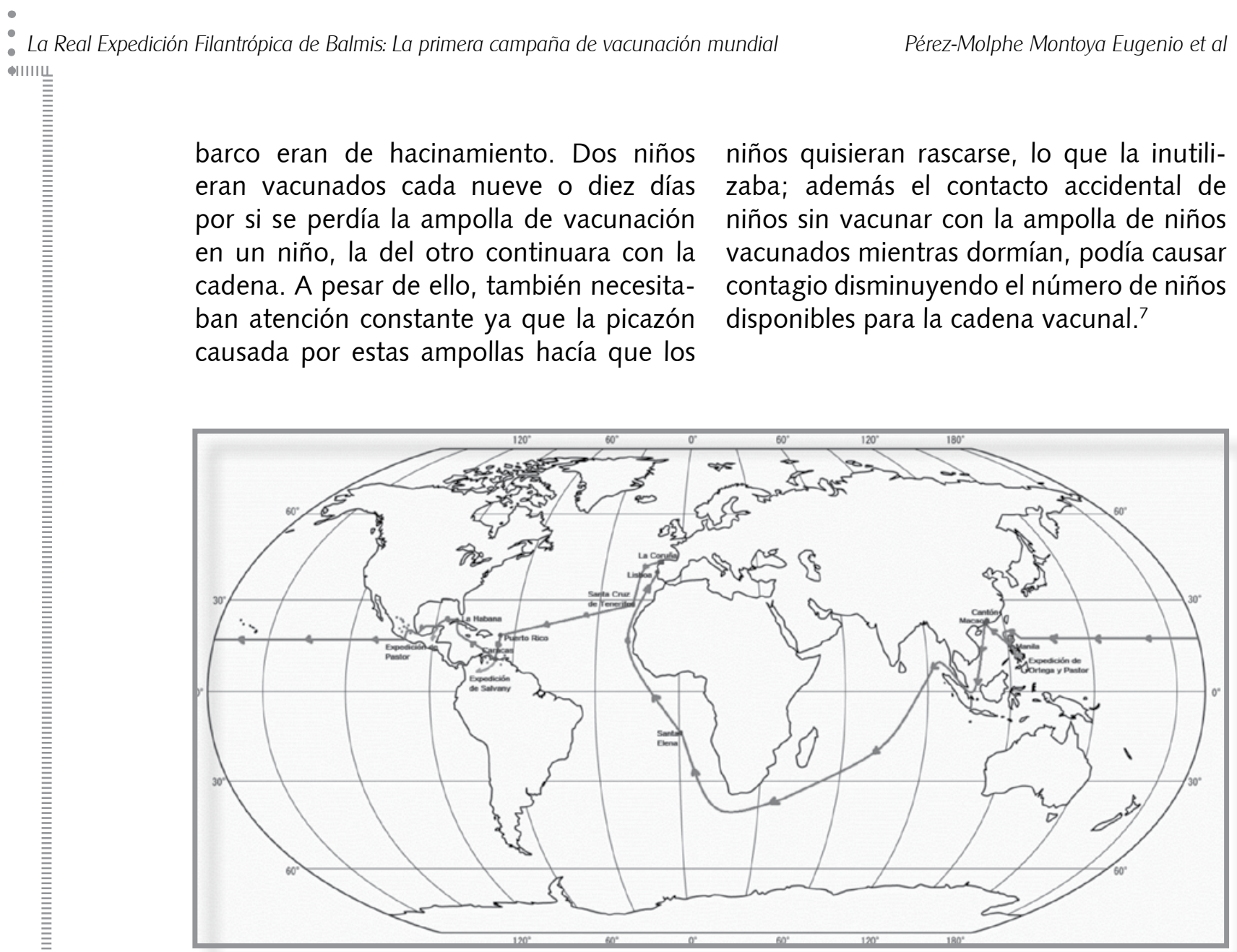

Figura 2. Mapa que indica la ruta seguida por la Real Expedición de Balmis. La expedición zarpó del puerto de La Coruña el 30 de noviembre de 1803 y llegó a Lisboa el 14 de agosto de 1806 tras introducir y difundir la vacuna contra la viruela en los territorios hispanos en América y Filipinas.

El 9 de diciembre arribaron al puerto de Santa Cruz de Tenerife donde se hicieron las primeras vacunaciones con gran alegría de la población y del gobierno local. ${ }^{2} \mathrm{El}$ 6 de enero de 1804 abandonaron la isla con rumbo a América y fue hasta el 9 de febrero que anclaron en Puerto Rico. ${ }^{6}$ Sin embargo, para frustración de Balmis, la vacuna ya había llegado por medio del doctor Francisco Oller Ferrer quien la trajo de la isla caribeña de Santo Tomás (territorio danés) utilizando como portadora una niña esclava de dos años. Entonces decidieron partir hacia Venezuela, rumbo a La Guaira, con sólo cuatro niños sin inocular. Debido a problemas en la navegación que los sacó de su rumbo y con el peligro inminente de quedarse sin vacuna porque solo quedaba un niño con la vacuna activa, Balmis decide tocar tierra en continente americano anclando su navío el 20 de marzo en la ciudad venezolana de Puerto Cabello. ${ }^{8}$ Tuvieron que viajar por 10 días para llegar a Caracas donde lograron vacunar a un total de 64 personas. Durante su estancia en esta ciudad, Balmis creó la primera Junta Central de Vacuna que se fundarían en la expedición y envió la vacuna a otros sitios de la Capitanía: Coro, Puerto Cabello, Ortiz, Santa María de Iripe, Tocuyo, Maracaibo, Cumaná e Isla Margarita. En esta misma ciudad, Balmis decide dividir en dos 
la expedición con la finalidad de propagar la vacuna con más rapidez. La subexpedición dirigida por Balmis zarpó en la corbeta María Pita hacia América del Norte el 8 de mayo de 1804, mientras que Salvany quedó al mando de la subexpedición que partió ese mismo día, en el barco San Luis, hacia el sur. ${ }^{6}$

Balmis quedó acompañado por 5 personas: el ayudante Antonio Gutiérrez Robledo, el practicante Francisco Pastor, los enfermeros Pedro Ortega y Antonio Pastor y la rectora Isabel Sendales y Gómez; además de todos los niños procedentes de Galicia. ${ }^{6}$ La primera parada fue en La Habana, el 26 de mayo de 1804, tras un viaje espantoso que mermó la salud de la tripulación, especialmente la de los niños. Allí la vacuna ya estaba impuesta por el médico Tomás Romay y Chacón, pero Balmis cooperó con el doctor Romay para su implantación y extensión por la isla. Al mismo tiempo solicitó al gobierno local 4 niños para continuar su viaje. Ante la falta de respuesta de las autoridades, Balmis optó por convencer a un joven del regimiento de Cuba y comprar 3 esclavas negras que le permitirían llevar la vacuna a la Nueva España. El 18 de junio zarpó la expedición hacia el puerto de Sisal en Yucatán donde llegaron a principios de julio. ${ }^{8}$

En Sisal, Balmis cayó enfermo con fiebre y diarrea severa. ${ }^{2}$ También se enteró que el doctor Miguel José Monzón ya había introducido la vacuna y que ésta era totalmente válida. ${ }^{8}$ Cuatro días más tarde arribaron a Mérida donde sí hubo vacunaciones con apoyo del gobierno local y en vista del entusiasmo generalizado decidió hacer una campaña por Centroamérica poniendo a cargo a su sobrino Francisco Pastor. El resto de los expedicionarios zarparon el 19 de junio del puerto de Sisal, llegando a Veracruz cuatro días más tarde donde de nuevo se toparon con la noticia de que la vacuna había sido perfectamente establecida por el doctor Alejandro García de Arboleya.6 El gobernador de Veracruz quería que Balmis se fuese lo antes posible ya que debía de cumplir la orden real de alojar, transportar y alimentar a los expedicionarios, que en realidad ya no eran necesarios en su ciudad. Por otro lado a los médicos locales no les convenía la presencia de Balmis porque administraba la vacuna gratuitamente, mientras que ellos la cobraban; además de que en esa época existía una hostilidad natural en las colonias hacia los funcionarios que venían directamente de España. Por estas razones el gobernador cedió diez soldados a Balmis en los que poder conservar el fluido fresco y abandonar así Veracruz el 1 de agosto rumbo a la Ciudad de México, donde dejaría a los niños que traía consigo desde La Coruña. ${ }^{6}$

La estancia en la capital distó por mucho de ser ideal. Además de que la vacuna ya había llegado, los expedicionarios se enfrentaron a un virrey hostil y a condiciones infrahumanas de alojamiento. Para empeorar las cosas algunos de los niños de la Casa de Expósitos, que por su frágil estado de salud no formaron parte de la cadena de vacunación durante las travesías y que Balmis había vacunado recientemente, murieron por las condiciones pésimas que el virrey Iturrigaray dispuso para su estancia; mas sin embargo, los miembros de la corte acusaron a Balmis de negligente y de que su vacuna era peligrosa. Tras una investigación organizada por el virrey todas las acusaciones fueron refutadas ${ }^{8}$ y Balmis decidió abandonar la ciudad en septiembre e ir a Puebla donde tuvo un excelente recibimiento. En los días siguientes vacunó a unas 9000 personas de esta ciudad. De Puebla fueron a Querétaro donde las vacunaciones estuvieron acompañadas por música. Desde ahí la expedición se dividió para cubrir más territorio: Antonio Gutiérrez realizó la ruta que pasó por Morelia, San Luis Potosí, Zacatecas y Guadalajara, mientras que la de Balmis tomó rumbo a Aguascalientes y Durango. También hubo 
vacunaciones de la expedición en Celaya, Guanajuato, Guadalupe, Fresnillo y Sombrerete (Figura 3).2,6,8 Tras esta ardua pero exitosa expedición por las provincias norteñas en la que Balmis enfermó de nuevo de disentería, fueron recolectados los niños mexicanos que llevarían la vacuna a Asia. De los 26 nuevos niños expedicionarios 6 fueron huérfanos entregados a Balmis por el prefecto de Zacatecas, otros 6 fueron "alquilados" (a 150 pesos cada uno) por
Gutiérrez en Guadalajara y el resto colectados en Querétaro y Fresnillo, prometiendo la devolución de los niños a la vuelta de la expedición. Balmis regresa a la capital a finales de diciembre de 1804 donde comenzó a organizar los preparativos del viaje que le permitiera llevar la vacuna al archipiélago filipino junto con Antonio Gutiérrez, Francisco y Antonio Pastor, Pedro Ortega, Isabel Sendales y los niños mexicanos portadores de la vacuna. ${ }^{2,6}$

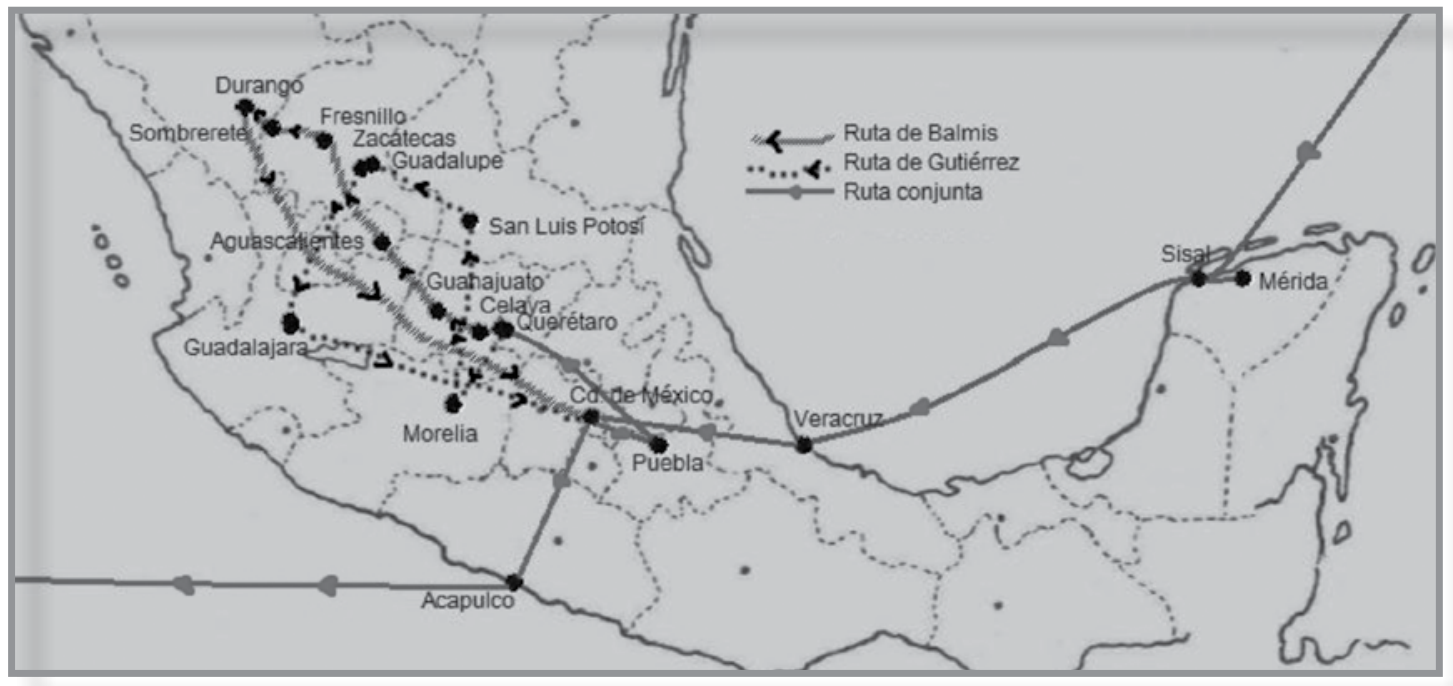

Figura 3. Mapa que muestra las principales ciudades mexicanas en las que la Real Expedición difundió la vacuna. Se indican las rutas que siguieron Francisco Xavier Balmis y Antonio Gutiérrez.

El 7 de febrero de 1805 zarpó la expedición del puerto de Acapulco a bordo del San Francisco de Magallanes, un barco regular de carga que tras muchas gestiones el virrey ordenó adaptar y concedió a Balmis para la travesía. Las condiciones de comodidad a bordo eran escasas, sobre todo para los niños que dormían en hamacas o jergones, lo que propició que a causa de los vaivenes del viaje sufrieran varias inmunizaciones accidentales. ${ }^{2,6}$ La expedición llegó a Manila el 6 de abril de 1805, donde fueron recibidos con alegría. Antonio Pastor y Pedro Ortega vacunaron en las islas del sur y Balmis se dirigió a Luzón. Se estima que entre abril y agosto de 1805 se vacunaron 20 mil personas en Filipinas; hasta se logró vacunar a una tribu hostil a la Corona después de haberse acordado una tregua con este fin. ${ }^{2}$ En Manila, Balmis volvió a enfermarse de diarrea disentérica y con una salud muy debilitada tomó la decisión de regresar a la península Ibérica dejando la dirección de la expedición por Filipinas a Antonio Gutiérrez, con la encomienda de que terminada su misión en el archipiélago debían de regresar con los niños mexicanos en el Magallanes para 
entregarlos a sus padres. ${ }^{6}$ Desde México, años más tarde, Antonio Gutiérrez e Isabel Sendales regresarían a España. ${ }^{2}$

El viaje de retorno de Balmis partió de Manila el 3 de septiembre de 1805 a bordo del navío La Diligencia con el propósito de pasar en su ruta por la isla de Macao. ${ }^{6} \mathrm{El}$ 10 de septiembre y tras un plácido viaje llegan a las costas de Macao donde quedaron atrapados en un terrible tifón que casi hunde la fragata y se llevó las vidas de 20 hombres. Por suerte Balmis, Francisco y Antonio Pastor y 3 los niños filipinos, encargados ahora de transportar la vacuna, salieron casi ilesos del percance y pudieron tocar tierra en canoas 6 días después de arribar a la costa. ${ }^{2}$ Fueron recibidos con entusiasmo ya que la vacuna había llegado tiempo antes a manos de los ingleses pero se perdió porque solo se guardó entre vidrios. Por tanto, las autoridades locales cooperaron en las vacunaciones. ${ }^{2,6} \mathrm{De}$ allí Balmis se dirigió a Cantón (actual China) con un solo niño portador del fluido vacunal y tras algunos conflictos con los apoderados comerciales realizó vacunaciones y enseñó a preservar la vacuna estableciendo Juntas de Vacuna. ${ }^{2,8}$ Regresó a Macao a finales de 1805 y en febrero de 1806 partió hacia Lisboa junto a Francisco y Antonio Pastor a bordo del Buen Jesús di Alem con pasajes regalados por el gobernador de Macao, Miguel de Arriaga, en muestra de su agradecimiento. ${ }^{2}$ Como parte de su ruta, el navío hizo escala en la isla inglesa de Santa Elena, donde Balmis se puso a disposición de las autoridades y se comenzaron con las vacunaciones a pesar de la rivalidad entre Francia y España en esa época. ${ }^{2,5}$

Finalmente, la fragata llegó a Lisboa en la tarde del 14 de agosto de 1806, 32 meses y 14 días después de que Balmis partiera con su expedición del puerto de La Coruña. El rey Carlos IV lo recibió como un héroe en Madrid el día 7 de septiembre de ese mismo año. ${ }^{2}$

\section{Logros y legados}

La expedición dirigida por Balmis fue la primera campaña global de vacunación y tuvo lugar 150 años antes de que se instaurara la Organización Mundial de la Salud y un siglo antes de la formación de la Organización Panamericana de la Salud. ${ }^{5}$ Desde el punto de vista organizativo, fue pionera en su planificación al estructurarse no solo como una campaña puntual de vacunación sino con el interés de perdurar y permanecer durante el tiempo. Para ello Balmis tenía claro que era necesario profesionalizar la salud pública local, transferirle tecnología y evaluar los aspectos médicos, económicos y sociales de la vacunación. ${ }^{3}$

Con esta finalidad se establecieron las llamadas Juntas de Vacunas en localidades estratégicas tanto de América como de Asia. En América destacan las de México, La Habana, Quito, Lima, Caracas, Puebla, Guadalajara, Santa Fe y La Paz. En ellas se enseñaron y perpetuaron los Reglamentos de vacunación. ${ }^{3}$ Estas instituciones lograron hacer grandes avances en la institucionalización de la sanidad en América, anteriormente en manos de las órdenes religiosas que en sus conventos-hospitales usaban una medicina eminentemente práctica y poco avanzada para la época. Además cada junta establecía su Reglamento de vacunación siguiendo como modelo el establecido en la Junta de Caracas pero adaptándolo a la realidad política y social de cada territorio. La vacunación estaba por encima de las luchas políticas, como lo pone de manifiesto el hecho de que desde la ciudad de Cuenca en el actual Ecuador, Simón Bolívar solicitó vacunas a la Junta de Caracas que estaba en zona realista (dominada por la monarquía española) para poder vacunar a sus tropas.,

En cuanto a Balmis, al año siguiente de su regreso a España Carlos IV lo nombró Cirujano de Cámara e Inspector General de la Vacuna en España. En 1810 volvió a México para observar y llevar registro 
del estado de la vacunación retornando en 1813 y llegando a una España devastada por su guerra de Independencia contra las tropas napoleónicas. Después de este año hizo su sexto y último viaje a América. ${ }^{2} \mathrm{El}$ 12 de febrero de 1819 murió Balmis en Madrid a sus 65 años de edad. ${ }^{11}$ Para este tiempo, había conseguido un estatus económico elevado y poseía buenas relaciones con comerciantes, médicos y clérigos importantes en Madrid y México. ${ }^{12}$

Gracias a su increíble hazaña, aproximadamente unas 250 mil personas, en su mayoría niños, fueron vacunados directamente por la expedición que dirigió. Un cuarto de millón de personas adicionales recibirían posteriormente la vacuna en América y Filipinas a través del personal sanitario que fue entrenado en las Juntas de Vacunas. ${ }^{2}$ Finalmente mencionar que la influencia de la expedición también se ha visto reflejada en obras literarias como la obra de teatro de Andrés Bello "Venezuela consolada", la novela "Saving the World" de la escritora de origen dominicano Julia Alvarez y en la composición poética "Oda a la expedición española para propagar la vacuna en América bajo la dirección de don Francisco Balmis" del poeta madrileño Manuel José Quintana. ${ }^{4,8}$

\section{| | | | | | | | | | | | | | | | | | | | | | | | | | | | | | | | | | | | | | | | | | | | | | | | | | | | | | | | | | | | | | | | | | | | | | | | | | | | | | | | | | | | | | | | | | | | | | | | | | | | | | | | ||}

\section{Bibliografía}

1. Tuells J. Francisco Xavier Balmis (1753-1819), a pioneer of international vaccination. J Epidemiol Community Health. 2002; 56:802.

2. Tuells J. El proceso de revisión a la traducción de Francisco Xavier Balmis del Tratado histórico y práctico de la vacuna, de Moreau de la Sarthe. Gac Sanit. 2012; 26 (4):372-5.

3. Asensi F. 2009. La Real expedición filantrópica de la vacuna (Xavier de Balmis /Josep Salvany) 1803 1806. Rev Chil Infect. 2009; 26 (6):562-7.

4. Franco-Paredes C. Lammoglia L. Santos-Preciado Jl. 2005. The Spanish Royal Philanthropic Expedition to Bring Smallpox Vaccination to the New World and Asia in the 19th Century. Clin Infect Dis. 2005; 41:1285-9.

5. Cortés JGR. Inicio de la Vacunación en la ciudad de Puebla, 1804-1814. En: Cuadernos de Trabajo número 30. Instituto de investigaciones HistóricoSociales. Universidad Veracruzana. Xalapa, Veracruz, 2008, pág. 1-83.
6. Góngora-Biachi RA. El bicentenario del inicio de la vacunación. Rev Biomed 1996; 7:241-4.

7. Herrera JC. Balmis y el sueño de la medicina de la Ilustración La Real Expedición Filantrópica de la Vacuna. En: Anatomía de la Historia. 2011.

8. Ramírez SM. El legado de la Real Expedición Filantrópica de la Vacuna (1803-1810): Las Juntas de Vacuna. Asclepio 2004; 56 (1):33-61

9. Rizzi M. Bicentenario de la expedición de la vacuna variólica y su introducción en Río de la Plata. Rev Med Urug. 2007; 23 (1):7-18

10. Tuells J. Ramírez SM. Francisco Xavier Balmis y las Juntas de Vacuna, un ejemplo pionero para implementar la vacunación. Salud Publ Mex. 2011; 53 (2):172-7

11. Tuells J. Duro JL. Los cinco testamentos de Francisco Xavier Balmis. Gaceta Médica de México. 2012; 148:411-8.

12. Tuells JV. Escenarios vitales de Francisco Xavier Balmis (1753-1819), Director de la Real Expedición Filantrópica de la Vacuna. An R Acad Med Comunitat Valenciana. 2011; 12:1-17. 